\title{
Genetics of hybridization between Drosophila simulans females and D. melanogaster males
}

\author{
MARIA C. CARRACEDO*, AMELIA SUAREZ, ANA ASENJ O \& PELAYO CASARES \\ Departamento de Biología Funcional, Area de Genética, Universidad de Oviedo, 33006 Oviedo, Spain
}

\begin{abstract}
Drosophila simulans and D. melanogaster are sibling cosmopolitan species with imperfect ethological isolation. Hybridization is easy between D. melanogaster females and D. simulans males, but the reciprocal cross has been traditionally considered as very scarce and little is known about the environmental and genetic factors that affect it. We used classical genetic analyses to determine the influence of each major chromosome on the breakdown of sexual isolation between females of $D$. simulans and $D$. melanogaster males. In addition, we have made a first attempt to locate the genetic systems involved in this process. At least two genes, or two groups of genes, are responsible for hybridization, located in the X chromosome and in the left arm of chromosome II. The inheritance mode of both genetic systems is different. The genes in the $\mathrm{X}$ chromosome show dominance for high levels of hybridization, whereas those in chromosome II show dominance for low levels. These results contrast with other investigations on the melanogaster subgroup, suggesting independent evolutionary events during the speciation process in each species.
\end{abstract}

Keywords: Drosophila melanogaster, Drosophila simulans, genetic analysis, sexual isolation.

\section{Introduction}

Understanding the genetic changes involved in speciation is one of the most important topics in evolutionary biology. The classical first step in speciation is the isolation of populations by geographical barriers (Mayr, 1942). During this period, genetic changes can happen by drift, differential adaptation and mutation, that may be the beginning of incompatibility genes, known as speciation genes (Zouros, 1989; Coyne, 1992). Hybrid sterility and/or inviability are the most effective mechanisms of reproductive isolation because they prevent gene flow between species. However, in terms of fitness at a population level, sexual isolation is perhaps the most important cause of speciation in animals, because it limits and prevents waste of time and energy (Futuyma, 1986).

There are several theories about the evolution of premating isolation. Fisher (1930) and Dobzhansky (1937) proposed that sexual isolation develops by natural selection against hybridization. Müller (1942) postulated that premating isolation is a by-product of genetic divergence in allopatric populations, and Nei (1976), extending Müller's hypothe-

${ }^{*}$ Correspondence. E-mail: pcg@sauron.quimica.uniovi.es sis, proposed that ethological isolation occurs mainly by random fixation of genes that control mating preferences or compatibility between both sexes. Although these theories are based on different principles, all agree on the necessity of genetic changes during the speciation process, changes that are specific to each particular evolutionary history (Gould, 1980; Lande, 1981, 1982; Templeton, 1982; Wright, 1982).

Despite the interest in speciation, little is known about the genetics of sexual isolation. Some studies have been undertaken with Drosophila species-pairs (Kawanishi \& Watanabe, 1981; Coyne, 1989, 1992; Carracedo et al., 1995) that show that genes for sexual isolation are widely distributed over the genome. However, there are differences in their inheritance modes, as some species have genes with additive effects (Carracedo et al., 1989; Izquierdo et al., 1992; Uenoyama \& Inoue, 1995), whereas others show dominance for high hybridization frequency (Coyne, 1989, 1992; Welbergen et al., 1992).

Determination of the genetic basis of biological traits causing reproductive isolation can be settled only by genetic crosses and mapping experiments. Location of such genes may help to understand the 
origin of species and to reconstruct the order of evolutionary changes. Genetic analysis, based on crosses between closely related species and segregation of discrimination traits and their linkage to mapped phenotypic or biochemical markers, permits the estimation of the number and location of genes involved in reproductive isolation. In general, studies of this type have been undertaken with species-pairs that produce at least one fertile hybrid sex, because genetic analyses of species that produce sterile or inviable hybrids of both sexes are difficult, and need elaborate schemes of crossings with marker strains to obtain lines with chromosomes of different genetic compositions (Welbergen et al., 1992; Carracedo et al., 1995; Uenoyama \& Inoue, 1995).

The present study analysed the genetics of female sexual isolation between Drosophila simulans females and D. melanogaster males. The two species are cosmopolitan and associated with human activities, and they are reproductively isolated, yielding unisexual sterile hybrids, males in this cross. Little is known about the genetics of this mating, because it has been traditionally considered as infrequent. However, in recent years several papers have shown that hybridization of D. simulans females with D. melanogaster males can easily happen in some populations or strains (Welbergen et al., 1992; Das et al., 1995; Uenoyama \& Inoue, 1995; Davis et al., 1996; Carracedo et al., 1997). The study investigated the location of genes affecting isolation of D. simulans females, using synthetic lines obtained by crosses between a multimarker strain and a population that had a very high hybridization value (Carracedo et al., 1997).

\section{Materials and methods}

A wild D. simulans population from the Seychelles Islands, whose females hybridized around 90 per cent with males of D. melanogaster from several strains (Carracedo et al., 1996), was sent to the authors by J. R. David in 1988. A D. simulans stock was received from the Bloomington Stock Centre (stock no. 2008). This was homozygous for several recessive markers: forked-2 (short bristles) on the $\mathrm{X}$ chromosome $\left(f^{2}: 1-56.7\right)$; net (altered wing veins) and brown (eye colour) on the two arms of the second chromosome (nt: 2-0.0, 2L; bw 2-104.5, 2R); and scarlet (eye colour) and ebony (black body colour) on the two arms of the third chromosome (st: 3-40.0, 3R; e: 3-60.0, 3L). Mutations brown and scarlet in the same individual give a peach-coloured eye. Map locations for $f^{2}, n t$ and $b w$ are taken from D. melanogaster, whose $\mathrm{X}$ and second chromosomes are homosequential to those of $D$. simulans (Lemeunier \& Ashburner, 1976, 1984). Locations of $s t$ and $e$ correspond to D. simulans (Ohnishi \& Voelker, 1979). The tiny fourth chromosome was not studied because markers were not available. Males of a D. melanogaster wild-type population captured in Asturias (Spain) in 1990 were used for hybridization estimates.

All stocks were maintained in bottles with $10 \mathrm{~mL}$ of food (made up from: baker's yeast $100 \mathrm{~g}$, sugar $100 \mathrm{~g}$, agar $12 \mathrm{~g}$, salt $2 \mathrm{~g}$, propionic acid $5 \mathrm{~mL}$, water $1000 \mathrm{~mL}$ ).

The effects of each chromosome on heterospecific mating propensity were assessed in the $F_{2}$ females from two crosses as follows.

1 Cross A: females of the marker strain $\times$ Seychelles males. From the progeny of this cross, three different $\mathrm{F}_{2}$ phenotypic classes were chosen: (i) A.1, homozygous for the mutation $f^{2}(\mathrm{X})$; (ii) A.2, homozygous for $f^{2}, n t$ and $b w$ (X and II); and (iii) A.3, homozygous for $f^{2}$, st and $e$ (X and III). For each of these phenotypes there are several genotypes which are schematized in Fig. 1.

2 Cross B: Seychelles females $\times$ males of the marker strain. The three $F_{2}$ female phenotypes chosen were: (i) B.1, homozygous for $n t, b w$ (II); (ii) B.2, homozygous for st,e (III); and (iii) B.3, homozygous for $n t, b w$ and st,e (II and III). Their corresponding genotypes are shown in Fig. 2.

To differentiate between homo- and heterozygous genotypes having the same phenotype, once the isolation test had been ended, each female was backcrossed with two males of the multimarker strain, and its genotype was determined from the presence or absence of recessive mutations in the progeny.

The crosses A and B were carried out by placing 20 pairs of adult virgins in a vial with food. From the $\mathrm{F}_{1}$ progeny, 20 pairs of adults, also virgins, were transferred to a new vial. Females from the $F_{2}$, homozygous for the different mutations described above, were tested for sexual isolation against males of D. melanogaster, and later their genotype was determined. A minimum of 20 and 30 vials was set up for each $F_{1}$ and $F_{2}$, respectively. A different number of females was tested in the different phenotypic classes, because some of them need the occurrence of specific crossing-overs to appear.

The level of sexual isolation was estimated by the frequency of hybridization in 'no-choice' mating experiments. To achieve this, $10 \quad \mathrm{~F}_{2}$ D. simulans females from one phenotypic class and $10 \mathrm{D}$. melanogaster males, newly emerged, were put into vials with food. Five days later, each female was individually placed into a new vial for 2 days. Female

(C) The Genetical Society of Great Britain, Heredity, 80, 17-24. 
hybridization was confirmed by the appearance of larvae in the vials; this method is equivalent to sperm presence in dissected females (Carracedo et al., 1998). Hybridization was measured under $21.5^{\circ} \mathrm{C}$ and 12:12 h light: dark conditions.

The hybridization frequencies of the $42 \mathrm{~F}_{2}$ genotypic classes shown in Figs 1 and 2 permit detection of the effect of each chromosome and arm on female sexual isolation, and the possible interactions between them.

\section{Results}

Hybridization in parental cultures

The female hybridization frequency from Seychelles was 88.79 per cent (103/116), and from the marker strain was 37.72 per cent (43/114). Comparison of these percentages by a contingency $\chi^{2}$-test results in a significant value $\left(\chi_{1}^{2}=69.45, P<0.001\right)$.

\section{Hybridization in $\mathrm{F}_{2}$}

To test the effect of arms and chromosomes on sexual isolation, the frequencies of hybridization of the different genotypes have been analysed using the log-linear scale following the methodology of Bishop et al. (1975).

First, the effect of the whole chromosomes has been examined in a four-way analysis, $2 \times 2 \times 2 \times 2$. Three factors correspond to genotypes in which each of the X, II and III chromosomes has two alternatives (levels): both chromosomes from the marker strain or both from Seychelles. The fourth factor is hybridization (yes or no). The factorial design is
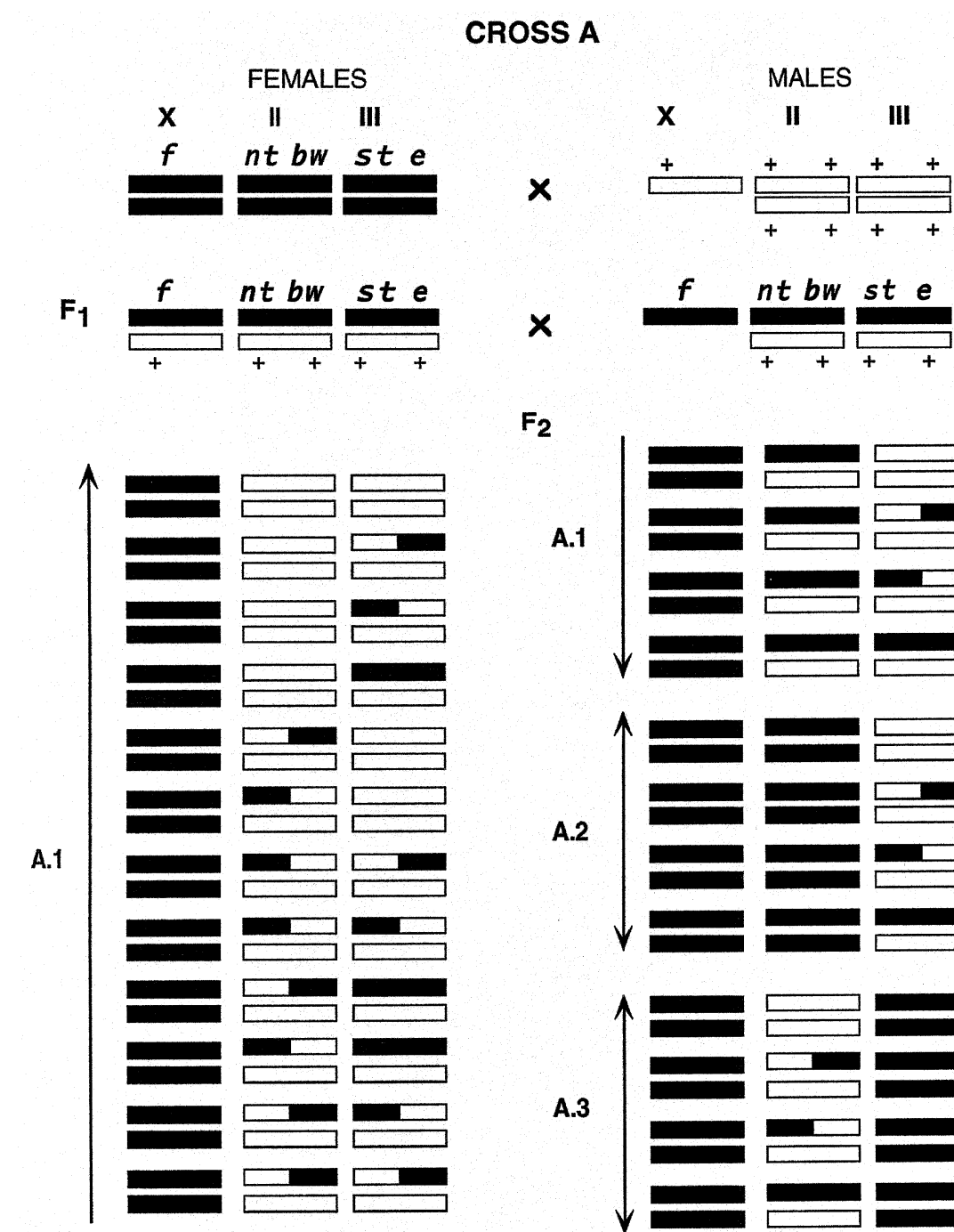

$F_{2}$

Fig. 1 Cross A: chromosomal composition of the Drosophila simulans parents, the $F_{1}$, and the $F_{2}$ genotypes chosen for analysis. Segments of the marker strain are shown in black and those of Seychelles in white. Groups A.1, A.2 and A.3 are homozygous for $\mathrm{X}, \mathrm{X}$ and II, and $\mathrm{X}$ and III chromosomes from the marker strain, respectively.

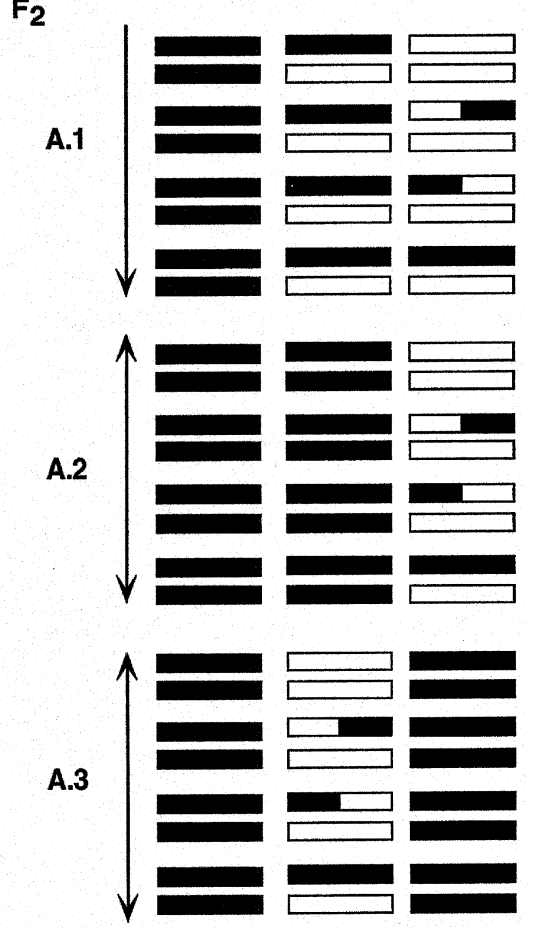


depicted in Fig. 3 together with the data of each genotype. The results of the analysis appear in Table 1.

Chromosomes $\mathrm{X}$ and II have a strong effect on isolation. Owing to this effect, a weak interaction between these chromosomes is also detected. No effect of chromosome III, as a whole, is found. This latter result, however, does not rule out the occurrence of genes with opposite effects in chromosome III that cancel each other out. To test this possibility a three-way analysis of frequencies $2 \times 2 \times 2$ was performed, in which two factors were the left and right arms of chromosome III, with two levels each (one or two doses from Seychelles), and the third factor was hybridization (yes or no). A scheme showing the different genotypes and their associated data is shown in Fig. 4. The nonsignificant results of the analysis (Table 2) confirm the lack of influence of chromosome III on sexual isolation.
A better knowledge of the influence of chromosomes $\mathrm{X}$ and II on isolation can be obtained from a four-way analysis $(3 \times 2 \times 2 \times 2)$, in which the different genotypes of the unimportant chromosome III have been pooled. The factors are: the $\mathrm{X}$ chromosome (three levels), the left and right arms of chromosome II (two levels each) and hybridization (yes or no). Figure 5 shows a drawing of the different genotypes used in the analysis and their corresponding hybridization data. The results of the analysis (Table 3) show the great importance of the $\mathrm{X}$ chromosome and the left arm of chromosome II, but no interaction between them. No effect of the right arm of chromosome II is indicated.

\section{Inheritance mode}

The effect of the genetic systems of the $\mathrm{X}$ and the left arm of chromosome II may be estimated if the

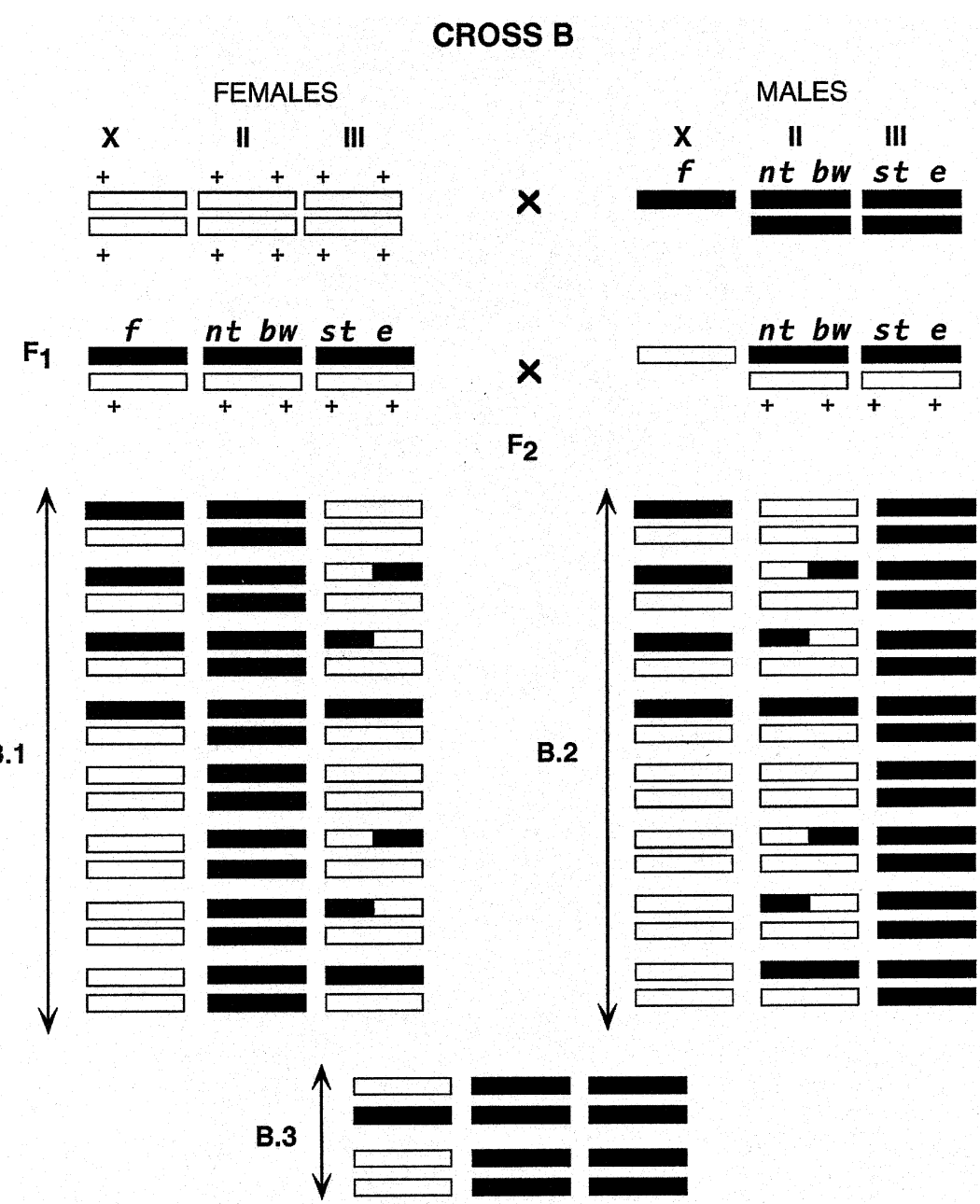

\begin{abstract}
Fig. 2 Cross B: chromosomal composition of the Drosophila simulans parents, the $F_{1}$, and the $F_{2}$ genotypes chosen for analysis. Segments of the marker strain are shown in black and those of Seychelles in white. Groups B.1, B.2 and B.3 are homozygous for II, III, and II and III chromosomes from the marker strain, respectively.
\end{abstract}




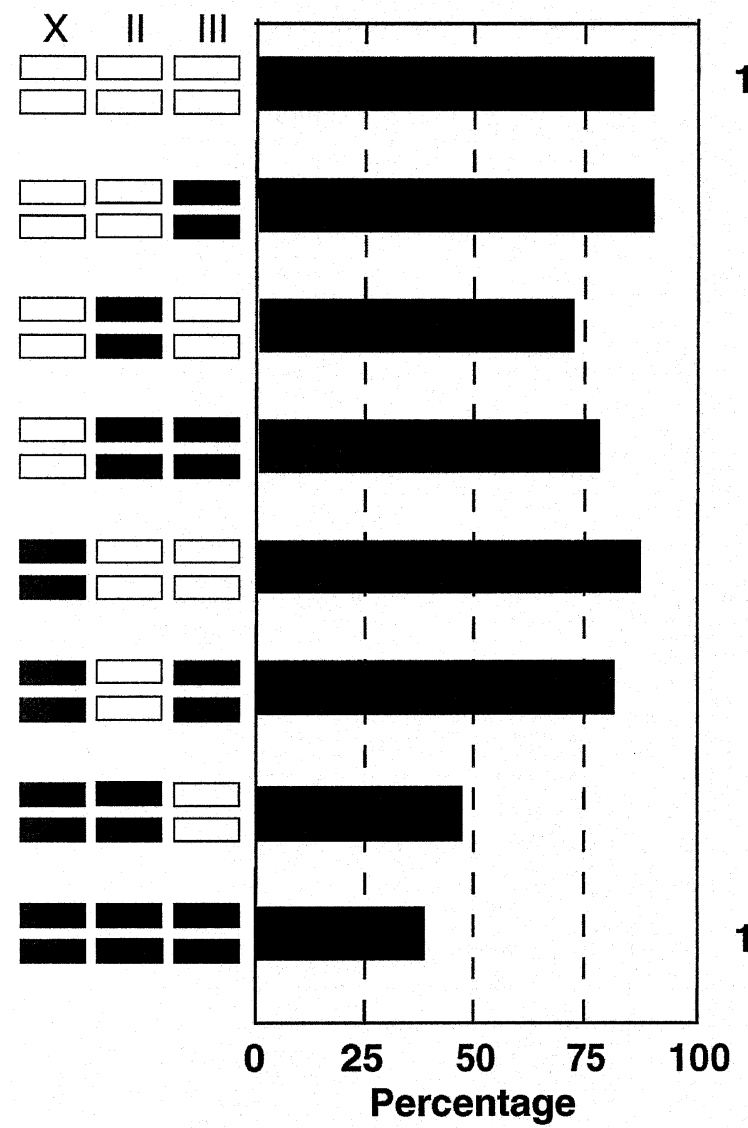

Fig. 3 Effects of chromosomes X, II and III on hybridization between female Drosophila simulans and male D. melanogaster. Chromosomes of the marker strain are shown in black and those of Seychelles in white. $N=$ number of females tested in each genotypic class.

Table 1 Effects of chromosomes X, II and III on hybridization frequency between female Drosophila simulans and male $D$. melanogaster from a four-way analysis in the log-linear scale

\begin{tabular}{lccc}
\hline Chromosomal effect & d.f. & $G$ & $P$ \\
\hline X-II-III & 1 & 0.29 & NS \\
X-III & 1 & 3.04 & NS \\
X-II & 1 & 4.63 & $<0.05$ \\
III & 1 & 0.10 & NS \\
II & 1 & 73.54 & $<0.001$ \\
X & 1 & 30.54 & $<0.001$ \\
\hline
\end{tabular}

116

90

70

63

70

62
$\mathbf{N}$

hybridization values are pooled for each chromosome independently.

$X$ chromosome Figure 6 shows the hybridization frequency of females with two, one or no X chromosomes from the marker strain. There are significant differences between them $\left(\chi_{2}^{2}=185.94, P<0.001\right)$, estimated by a test of variance for homogeneity of binomial distributions (Snedecor \& Cochran, 1967). The lowest value corresponds to the homozygote for the marker mutation, whereas heterozygous and wild-type homozygous chromosomes are not different. These results suggest that the gene for sexual isolation in the $\mathrm{X}$ chromosome has a dominant inheritance mode.

Table 2 Effect of the L (left) and R (right) arms of chromosome III on hybridization frequency between female Drosophila simulans and male D. melanogaster from a three-way analysis in the log-linear scale

\begin{tabular}{lccc}
\hline Chromosomal effect & d.f. & $G$ & $P$ \\
\hline III L-III R & 1 & 0.05 & NS \\
III L & 1 & 0.04 & NS \\
III R & 1 & 0.03 & NS \\
\hline
\end{tabular}

(C) The Genetical Society of Great Britain, Heredity, 80, 17-24. 
Left arm of chromosome II The $\mathrm{F}_{2}$ female genotypes can be classified in three groups according to the left arm of chromosome II, groups whose hybridization values appear in Fig. 6. There are differences among them $\left(\chi_{2}^{2}=156.48, \quad P<0.001\right)$

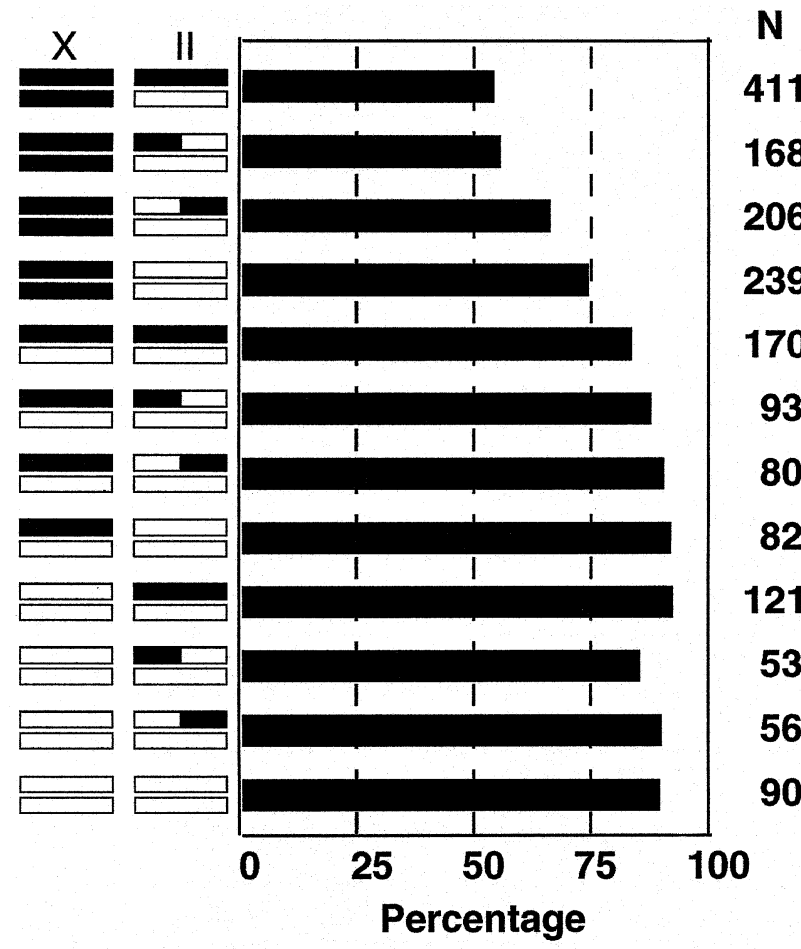

Fig. 5 Effects of chromosome $X$ and the left and right arms of chromosome II on hybridization between female Drosophila simulans and male D. melanogaster. Segments of the marker strain are shown in black and those of Seychelles in white. $N=$ number of females tested in each genotypic class.

Table 3 Effect of X and II chromosomes on hybridization frequency between female Drosophila simulans and male D. melanogaster from a four-way analysis in the log-linear scale

\begin{tabular}{lccc}
\hline Chromosomal effect & d. f. & $G$ & $P$ \\
\hline X-II L-II R & 2 & 0.70 & NS \\
II L-II R & 1 & 1.54 & NS \\
X-II L & 2 & 2.02 & NS \\
X-II R & 2 & 4.05 & NS \\
X & 2 & 174.09 & $<0.001$ \\
II L & 1 & 22.89 & $<0.001$ \\
II R & 1 & 1.57 & NS \\
\hline
\end{tabular}

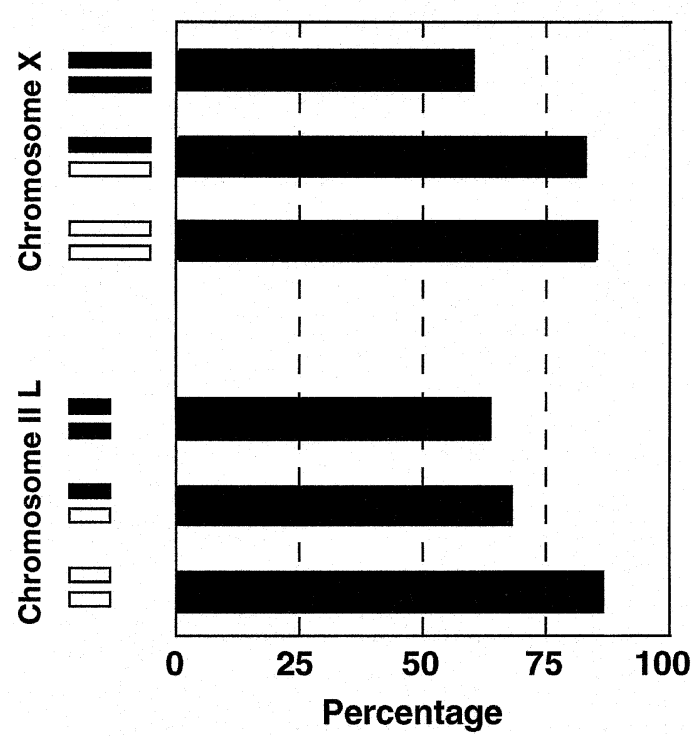

$\mathbf{N}$

1196

772

650

905

1016

1111

Fig. 6 Effects of chromosomes and arms on hybridization between female Drosophila simulans and male D. melanogaster. Top: X chromosome. Bottom: left arm of chromosome II. Segments of the marker strain are shown in black and those of Seychelles in white. $N=$ number of females tested in each genotypic class.

attributable to the highest value corresponding to the class homozygous for Seychelles, but there is no difference between the other two classes. The inheritance mode of this genetic system is dominant for low hybridization values, because the presence of a marker chromosome decreases hybridization.

\section{Discussion}

The location of genes affecting behavioural traits in species for which balanced chromosomes associated with marker mutations are not available is difficult. Some authors have reduced this problem by using synthetic lines, in which chromosome fragments from one species are introgressed into the genome of another (Coyne \& Kreitman, 1986; Coyne, 1992; Orr, 1992). This methodology has been used in genetic studies concerning reproductive isolation between related species, but only in species that yield at least one fertile sex in their progeny. The present study shows that it is possible to investigate chromosomal effects and gene location of speciation traits in species that yield unisexual and sterile hybrid progeny. We are aware that the power of our genetic analysis would increase if the number of 
available marker mutations in D. simulans were higher.

The present study detected at least two genes with a large effect on mating discrimination between females of D. simulans and D. melanogaster males. One is located in the $\mathrm{X}$ chromosome, linked to the mutation forked (1: 56.7); the other is in the left arm of chromosome II, linked to net (2: 0.0$)$. This is a minimum estimate of the number of major genes for this trait. It is also possible that there are other genes with minor effects that cannot be detected in this study. The gene action is different for the genes in each chromosome, because the gene in the $\mathrm{X}$ chromosome decreases isolation and is recessive, whereas the gene in chromosome II increases isolation and shows dominance.

Different results were found by Uenoyama \& Inoue (1995) studying premating isolation in the same pair of species as in the present study. They located at least two genes which act additively, one in chromosome II and the other in III, whereas the $\mathrm{X}$ chromosome was unimportant.

The differences in location and gene action between our results and those of Uenoyama \& Inoue (1995) are not too surprising. From an evolutionary point of view we might expect premating isolation genes to accumulate in species between which sexual isolation is not total, as occurs in the D. simulans and D. melanogaster pair. In such a case, geographically isolated populations of the same species could have different genes affecting the same trait. Uenoyama \& Inoue (1995) examined premating isolation in a Japanese population of D. simulans and we do so in a population from the Seychelles. These two populations may have experienced different evolutionary events that differentiate them genetically. It is known that $D$. simulans from the Seychelles differ from other conspecific populations in pheromones (Jallon \& David, 1987) and in mitochondrial races (Solignac \& Monnerot, 1986; Baba-Aissa et al., 1988), probably because of a founder effect. In short, the above supports the hypothesis of a wide distribution of isolation genes throughout the genome, and the possibility of accumulation of several genes with large effects during the speciation process (Templeton, 1982).

If different speciation genes can accumulate in isolated populations of the same species and can be revealed, it is obvious that this can also happen when different pairs of related species are studied, as some theories predict (Gould, 1980; Templeton, 1982; Wright, 1982); for instance, females of D. melanogaster bear genes for isolation from D. simulans males in all the three major chromo- somes, mainly in II and III (Carracedo et al., 1995), whereas females of $D$. simulans carry genes for isolation from D. sechellia and D. mauritiana males in chromosomes II and III, the X chromosome having no effect (Coyne, 1989, 1992). In addition to different gene locations, there were differences in the number of genes detected in each study, the relative weight of the chromosomes, and the inheritance modes of the corresponding genetic systems. It is clear then that the type and the action of the genes involved in sexual isolation may be different depending on the particular evolutionary forces that act in each speciation process.

\section{Acknowledgements}

This work was supported by the Ministry of Education and Science of Spain (DGICYT Grant DG-94-PB-1347).

\section{References}

BABA-AISSA, F., SOLIGNAC, M., DENNEBOUY, N. AND DAVID, J. R. 1988. Mitochondrial DNA variability in Drosophila simulans: quasi absence of polymorphism within each of the three cytoplasmic races. Heredity, 61, 419-426.

BISHOP, Y. M. M., FIENBERG, S. E. AND HOLLAND, P. W. 1975. Discrete Multivariate Analysis: Theory and Practice. MIT Press, Cambridge, MA.

CARRACEDO, M. C., GARCIA-FLOREZ, L. AND SAN MIGUEL, E. 1989. Sexual maturation in Drosophila melanogaster females and hybridization with D. simulans males: a study of inheritance modes. J. Hered., 80, 157-158.

CARRACEDO, M. C., PIÑEIRO, R. AND CASARES, P. 1995. Chromosomal substitution analysis of receptivity and sexual isolation in Drosophila melanogaster females. Heredity, 75, 541-546.

CARRACEDO, M. C., ASENJO, A. AND CASARES, P. 1998. Inheritance mode of Drosophila simulans female mating propensity with $D$. melanogaster. J. Hered. (in press).

COYNE, J. A. 1989. Genetics of sexual isolation between two sibling species, Drosophila simulans and Drosophila mauritiana. Proc. Natl. Acad. Sci. U.S.A., 86, 5464-5468.

COYNE, J. A. 1992. Genetics of sexual isolation in females of the Drosophila species complex. Genet. Res., 60, 25-31.

COYNE, J. A. AND KREITMAN, M. 1986. Evolutionary genetics of two sibling species, Drosophila simulans and D. sechellia. Evolution, 40, 673-691.

DAS, A., MOHANTY, S., CAPY, P. AND DAVID, J. R. 1995. Mating propensity of Indian Drosophila melanogaster populations with $D$. simulans: a nonadaptive latitudinal cline. Heredity, 74, 562-566.

DAVIS, A. W., ROOTE, J., MORLEY, T., SAWAMURA, K., HERRMANN, S. AND ASHBURNER, M. 1996. Rescue of hybrid sterility in crosses between D. melanogaster and D. simulans. Nature, 380, 157-159. 
DOBZHANSKy, TH. 1937. Genetics and the Origin of Species. Columbia University Press, New York.

FISHER, R. A. 1930. The Genetical Theory of Natural Selection. Clarendon Press, Oxford.

FUTUYMA, D. J. 1986. Evolutionary Biology. Sinauer, Sunderland, MA.

GOULD, s. J. 1980. Is a new and general theory of evolution emerging? Paleobiology, 6, 119-130.

IZQUIERDO, J. I., CARRACEDO, M. C., PIÑEIRO, R. AND CASARES, P. 1992. Response to selection for increased hybridization between Drosophila melanogaster females and D. simulans males. J. Hered., 83, 100-104.

JALLON, J. M. AND DAVID, J. R. 1987. Variations in cuticular hydrocarbons among the eight species of the Drosophila melanogaster subgroup. Evolution, 41, 294-302.

KAWANISHI, M. AND WATANABE, T. K. 1981. Genes controlling courtship song and mating preference in Drosophila melanogaster, D. simulans, and their hybrids. Evolution, 35, 1128-1133.

LANDE, R. 1981. Models of speciation by sexual selection on polygenic traits. Proc. Natl. Acad. Sci. U.S.A., 78, 3721-3725.

LANDE, R. 1982. Rapid origin of sexual isolation and character divergence in a cline. Evolution, 36, 213-223.

LEMEUNIER, F. AND ASHBURNER, M. 1976. Relationship within the melanogaster species subgroup of the genus Drosophila (Sophophora). I. Inversion polymorphism in D. melanogaster and D. simulans. Proc. R. Soc. B, 139, $137-157$.

LEMEUNIER, F. AND ASHBURNER, M. 1984. Relationship within the melanogaster species subgroup of the genus Drosophila (Sophophora). IV. The chromosomes of two new species. Chromosoma, 89, 343-351.

MAYr, E. 1942. Systematics and the Origin of Species. Columbia University Press, New York.
MÜLLER, H. J. 1942. Isolating mechanisms, evolution and temperature. Biol. Symp., 6, 71-125.

NEI, M. 1976. Mathematical models of speciation and genetic distance. In: Karlin, S. \& Nevo, E. (eds) Population Genetics and Ecology, pp. 723-765. Academic Press, New York.

OHNISHI, s. AND VOELKER, R. A. 1979. Comparative studies of allozyme loci in Drosophila simulans and D. melanogaster. II. Gene arrangement on the third chromosome. Jap. J. Genet., 54, 203-209.

ORR, H. A. 1992. Mapping and characterization of a 'speciation gene' in Drosophila. Genet. Res., 59, 73-80.

SNEDECOR, G. W. AND COCHRAN, w. G. 1967. Statistical Methods, 6th edn. Iowa State University Press, Ames, IA.

SOLIGNAC, M. AND MONNEROT, M. 1986. Race formation, speciation and introgression within the three homosequential species Drosophila simulans, D. mauritiana and D. sechellia inferred from their mitochondrial DNA analysis. Evolution, 40, 531-539.

TEMPLETON, A. R. 1982. Adaptation and integration of evolutionary forces. In: Milkman R. (ed.) Perspectives on Evolution, pp. 15-31. Sinauer, Sunderland, MA.

UenoyAmA, T. AND INOUE, Y. 1995. Genetic studies on premating isolation in Drosophila simulans. I. A D. simulans line highly crossable with $D$. melanogaster. Jap. J. Genet., 70, 365-371.

WELBERGEN, P., VAN DIJKEN, F. R., SCHARLOO, W. AND KOEHLER, W. 1992. The genetic basis of sexual isolation between Drosophila melanogaster and D. simulans. Evolution, 46, 1385-1398.

WRIGHT, s. 1982 . The shifting balance theory and macroevolution. Ann. Rev. Genet., 16, 1-19.

zouros, E. 1989. Advances in the genetics of reproductive isolation in Drosophila. Genome, 31, 211-220. 